\title{
Reduced density spheroplastic based on hollow phenol-formaldehyde microspheres and epoxy resin
}

\author{
(C) Vladimir Yu. Chukhlanov, ${ }^{1}{ }^{+}$Kirill V. Smirnov, ${ }^{2}$ and Natalia V. Chukhlanova ${ }^{3}$ \\ ${ }^{1}$ Department of Chemical Technology; ${ }^{2,3}$ Department of Biology and Ecology. \\ Alexander Grigorievich and Nikolay Grigorievich Stoletovs State University of Vladimir. \\ Gorkogo St., 87. Vladimir, 600000. Vladimir Region. Russia. \\ Phone: ${ }^{1)}+7$ (4922) 47-99-46; ${ }^{2)}+7$ (4922) 47-97-53; ${ }^{2}+7$ (904)030-08-61. \\ E-mail: ${ }^{1)}$ chukhlanov11@gmail.com; ${ }^{2)}$ kirillv.smirnov@yandex.ru; ${ }^{3)}$ natalyferre@yandex.ru
}

\begin{abstract}
*Supervising author; ${ }^{+}$Corresponding author
Keywords: synthetic foams, phenol formaldehyde microspheres, epoxy resin, adhesion, thermal insulation, density.
\end{abstract}

\section{Abstract}

In this article the physical-mechanical, thermal and electrical properties of spheroplastic based on epoxy resin ED-20 and hollow phenol-formaldehyde microspheres were studied. The samples were obtained by mixing an epoxy resin, cured with polyethylene polyamine, with hollow phenol-formaldehyde microspheres, poured into a mold and then cured at room temperature. The influence of the filler on the kinetics of the interaction of epoxy oligomer and aliphatic polyamine was studied. The effect of reducing the time of gel formation may occur due to the possible presence of reactive groups on the surface of microspheres. The experiments showed that the introduction of hollow phenol-formaldehyde microspheres in General leads to a slight decrease in the gel formation time. It is established that the introduction of hollow microspheres into the composition leads to a decrease in the density of the finished composition. The impact strength of spheroplastic was determined in accordance with GOST 4647-2015 "Method of Charpy impact strength determination" (ISO 179-1: 2010, NEQ). The introduction of hollow microspheres into the composition leads to a change in the impact strength of the composition in the direction of its decrease. A similar trend is observed in the study of the strength in the separation from the substrate of different materials. The coefficient of thermal conductivity was determined in a stationary mode on the device ITP-MG4"100" GOST 7076-99 "Method for determining the thermal conductivity and thermal resistance in a stationary thermal regime." Studies have shown that an increase in the content of hollow microspheres in the composition to $15 \%$ leads to a gradual decrease in the thermal conductivity coefficient to $0.74 \mathrm{~W} / \mathrm{m} \cdot \mathrm{K}$. The studied materials can be used as thermal insulation materials and for the manufacture of products used in various fields of science and technology.

\section{References}

[1] N.Yu. Budylin, A.V. Shapagin, R.R. Khasbiullin, and A.E. Chalykh. Miscibility, diffusion and hardening in epoxy oligomer - diaminodiphenyl sulfone system. Butlerov Communications. 2013. Vol.36. No.10. P.107-110. ROI: jbc-02/13-36-10-107

[2] V.Yu. Chuklanov, A.N. Alekseenko. The use of syntactic foam plastics with silicone binder in construction. Building materials. 2001. No.6. P.26-27. (russian)

[3] N.N. Smirnova. Interpolyelectrolyte complexation of sulfonate-containing aromatic polyamides in aqueous solutions. Butlerov Communications. 2018. Vol.53. No.2. P.87-93. DOI: 10.37952/ROI-jbc$01 / 18-53-2-87$

[4] D.K. Mendalieva, Z.Ha. Kunasheva, J.B. Yakupova, R.I. Kuzmina, and I.P. Shirokov. Development of composite materials for the construction of motorways on the basis of oil slime and drilling mud residue. Butlerov Communications. 2013. Vol.36. No.12. P.137-139. ROI: jbc-02/13-36-12-137

[5] V.Yu. Chukhlanov, N.N. Smirnova, N.V. Chukhlanova, and E.E. Mastalygina. Syntactic foams based on hollow ceramic microspheres and binder of oligomethylsilsesquioxane. Butlerov Communications. 2018. Vol.56. No.10. P.107-111. DOI: 10.37952/ROI-jbc-01/18-56-10-107 